\title{
Tratados que requieren la aprobación del Congreso de la República del Perú*
}

\author{
Gattās Abugattās*
}

\section{RESUMEN}

Este trabajo presenta la problemática en torno a la aplicación de los artículos 56 y 57 de la Constitución Política del Perú, referidos a los supuestos en los que un tratado requiere o no ser aprobado por el Congreso de la República antes de que el presidente manifieste el consentimiento del Estado en obligarse por él. Planteado el problema, analiza cada uno de los supuestos en los que la Constitución exige que un tratado sea aprobado por el Congreso de la República, a la luz de la doctrina, de la práctica peruana sobre la materia, así como de las normas vigentes y propuestas normativas.

Palabras clave: Tratados, celebración de tratados, perfeccionamiento interno de tratados en el Perú, aprobación de tratados por el Congreso de la República del Perú, artículo 56 y artículo 57 de la Constitución Política del Perú.

\section{Treaties requiring Congress approval in Peru}

\section{Abstract}

This paper presents the problems regarding the application of articles 56 and 57 of the Political Constitution of Peru, referring to cases in which a treaty requires or not to be approved by the Congress before the President express the consent of the State to be bound by it. Raised the problem, this paper analyzes each case in which the Constitution requires the Congress approval, considering the doctrine, the Peruvian practice on the matter, as well as the rules in force and normative proposals.

Keywords: Treaties, treaties conclusion, treaties approval by the Congress of Peru, article 56 and article 57 of the Political Constitution of Peru.

* Doctor en Derecho, máster en Diplomacia y Relaciones Internacionales, y abogado (licenciado en Derecho). Profesor ordinario principal de Derecho Internacional y Relaciones Internacionales en la Pontificia Universidad Católica del Perú. Correo electrónico: gabugattas@pucp.edu.pe

iD https://orcid.org/0000-0002-7237-7865 


\section{Problemática en torno a la aprobación de tratados}

En la tipología de los tratados se hace una distinción entre aquellos llamados simples o simplificados y los denominados complejos o solemnes. Esta clasificación se centra en la exigencia o no del Derecho interno de cada Estado de que, durante el proceso de celebración de un tratado, un organismo estatal, usualmente el Legislativo, deba revisar el texto autenticado y aprobarlo antes de que dicho Estado pueda manifestar su consentimiento en obligarse por el tratado.

De esta manera, si el tratado requiere ser aprobado antes de que el Estado manifieste su consentimiento en obligarse por él, será considerado solemne o completo; de no requerir tal aprobación, se le llamará simple o simplificado. Ahora bien, en la medida en que la exigencia o no de tal aprobación depende del derecho interno de cada Estado, un mismo tratado podrá ser considerado solemne por unos y simple por otros.

La revisión de un tratado a la luz del derecho interno de cada Estado para determinar si su celebración requerirá o no un acto interno de aprobación previa, ocurre luego de la etapa de la autenticación del texto del tratado y antes de la etapa de la manifestación del consentimiento del Estado en obligarse por él. Se realiza en una etapa intermedia en la que se forma la voluntad del Estado de obligarse o no por el tratado (Remiro Brotons et al., 2007, p. 365). Etapa que en el Perú se conoce con el nombre de «perfeccionamiento interno de los tratados».

Ahora bien, la necesidad de que un organismo estatal revise y apruebe el tratado como condición previa a la manifestación del consentimiento de dicho Estado en obligarse por el tratado, depende de la materia regulada en él. Como recuerda Novak (2013), citando a Fernández Maldonado:

La necesidad de esta distinción y de establecer dos procedimientos de celebración de tratados según la materia, data de muy antiguo. Locke, Rousseau y Tocqueville reconocían en su tiempo que la acción exterior del Estado precisaba de mayor libertad y flexibilidad para el Poder Ejecutivo, por lo que el Parlamento — debido al número de representantes, su inestabilidad y heterogeneidad, además de su tradicional lentituddebía abstenerse de participar salvo en aspectos puntuales y de importancia sustantiva. (p. 1046)

En este orden de ideas, las normas constitucionales de cada Estado suelen ser las encargadas de determinar las materias que, contenidas en el texto de un tratado, hacen que este requiera de una aprobación previa. El problema es que no siempre esas normas constitucionales son lo suficientemente claras; así, por ejemplo, la Constitución para la República del Perú de 1979, establecía lo siguiente: 
Artículo 102. Todo tratado internacional debe ser aprobado por el Congreso, antes de su ratificación por el Presidente de la República.

Artículo 103. Cuando un tratado internacional contiene una estipulación que afecta una disposición constitucional, debe ser aprobado por el mismo procedimiento que rige la reforma de la Constitución, antes de ser ratificado por el Presidente de la República.

Artículo 104. El Presidente de la República puede, sobre materias de su exclusiva competencia, celebrar o ratificar convenios internacionales con Estados extranjeros y organizaciones internacionales o adherir a ellos sin el requisito previo de la aprobación del Congreso. En todo caso debe dar cuenta inmediata a este.

Fue precisamente el último de los artículos citados el que, bajo la vigencia de la Constitución de 1979, generó la mayor cantidad de problemas. En la práctica, los presidentes celebraban una amplia cantidad tratados sin la aprobación previa del Congreso, alegando que aquellos versaban sobre «materias de su exclusiva competencia». La imprecisión de esta frase:

[...] originó una serie de problemas de competencia entre el Parlamento y el Ejecutivo, tal como ocurrió cuando este último celebró a sola firma los denominados Convenios Pesqueros con la Unión Soviética en 1988, o cuando suscribió el conocido Convenio Antidrogas en 1991. La fórmula utilizada por la Constitución de 1979 era muy ambigua, generando algunos problemas de interpretación [...] Fernández Maldonado encontró que la Constitución de 1979 señalaba las competencias exclusivas del Presidente en forma dispersa y poco clara. Más aún, comprobó que dichas materias no eran del todo exclusivas del Presidente, entrando también dentro del campo de acción del Congreso. Como ejemplo citaba el caso de la potestad reglamentaria, como atributo del Poder Ejecutivo (art. 211, inc. 11) pero cuya regulación correspondía al Parlamento (Novak, 2013, p. 1047).

Esta situación llevó a que el Congreso de la República, al aprobar en 1992 la ley 25397, Ley de Control Parlamentario sobre los actos normativos del Presidente de la República, dedicara en esta todo su capítulo IV a los tratados celebrados por el Presidente sin la aprobación del Congreso, a los que llamó «convenios internacionales ejecutivos», con la finalidad de establecer algunos límites en su celebración.

De acuerdo con lo establecido en el artículo 28 de la citada ley, dichos convenios internacionales ejecutivos:

- No podían contener disposiciones que supongan la modificación o derogación de normas constitucionales.

- No podían contener disposiciones que supongan la modificación o derogación de normas legales o que exijan desarrollo legislativo para su cumplimiento.

- No podían contener disposiciones sustantivas en materia de derechos humanos. 
- No podían contener disposiciones que supongan compromisos de reforma de la organización y los procesos judiciales ${ }^{1}$.

Además, el artículo 29 de la ley 25397 establecía que los convenios internacionales ejecutivos formaban parte del ordenamiento jurídico nacional, pero con rango inmediato superior al de decreto supremo ${ }^{2}$. Esto, pese a que el artículo 101 de la Constitución de 1979 otorgaba rango supralegal a los tratados celebrados por el Estado 3 .

Frente a toda esta situación, la Constitución Política del Perú de 1993, al regular los casos en los que un tratado requiere o no la aprobación del Congreso de la República antes de la manifestación del consentimiento del Estado en obligarse por él, intentó corregir los problemas identificados en su predecesora y, para ello, propuso el siguiente articulado:

Artículo 56.- Los Tratados deben ser aprobados por el Congreso antes de su ratificación por el Presidente de la República, siempre que versen sobre las siguientes materias:

1.- Derechos Humanos

2.- Soberanía, dominio o integridad del Estado.

3.- Defensa Nacional

4.- Obligaciones financieras del Estado

También deben ser aprobados por el Congreso los Tratados que crean, modifican o suprimen tributos; los que exigen modificación o derogación de alguna ley y los que requieren medidas legislativas para su ejecución.

Artículo 57.- El Presidente de la República puede celebrar o ratificar Tratados o adherir a estos sin el requisito de la aprobación previa del Congreso en materias no contempladas en el artículo precedente. En todos esos casos, debe dar cuenta al Congreso.

Cuando el Tratado afecte disposiciones constitucionales debe ser aprobado por el mismo procedimiento que rige la reforma de la Constitución, antes de ser ratificado por el Presidente de la República.

\footnotetext{
1 El artículo 28 de la ley 25397 señalaba que: «Los convenios internacionales ejecutivos no pueden contener pactos que supongan modificación o derogación de normas constitucionales o legales o exijan desarrollo legislativo para su cumplimiento, no preceptos sustantivos en materia de derechos humanos ni compromisos de reforma de la organización y los procesos judiciales».

2 Dicho artículo 29 dispuso que: «Los convenios internacionales ejecutivos forman parte del ordenamiento jurídico nacional y tienen rango de decreto supremo. En caso de conflicto entre un convenio internacional ejecutivo y un decreto supremo, prevalece el primero".

3 En efecto, el artículo 101 de la Constitución de 1979 precisaba que: «Los tratados internacionales celebrados por el Perú con otros Estados forman parte del derecho nacional. En caso de conflicto entre el tratado y la ley, prevalece el primero".

Es importante recordar que el artículo 105 de la misma Constitución dispuso que: «Los preceptos contenidos en los tratados relativos a derechos humanos, tienen jerarquía constitucional. No pueden ser modificados, sino por el procedimiento que rige para la reforma de la Constitución».
} 
La denuncia de los Tratados es potestad del Presidente de la República, con cargo de dar cuenta al Congreso.

En el caso de los Tratados sujetos a aprobación del Congreso, la denuncia requiere aprobación previa de este.

Estos artículos, si bien regulan el tema de manera mucho más precisa, no han sido ajenos a algunas críticas e interpretaciones diversas y hasta contradictorias. En la práctica, la aplicación de estas normas suele enfrentar al Ministerio de Relaciones Exteriores, que procura siempre evitar el trámite de aprobación de tratados por parte del Congreso de la República, con este último que, pese a su justo deseo de defender su fuero, mantiene aún ciertas "prácticas parlamentarias» que, en algunos casos, exigen un ejercicio de gran paciencia.

La situación descrita motivó, incluso, que el 15 de marzo de 2018 se presente el «Proyecto de Ley N²571/2017-CR, Ley de Desarrollo Constitucional sobre el Perfeccionamiento Interno de los Tratados», que busca esclarecer los supuestos en los que los tratados requieren o no la aprobación del legislativo, de acuerdo con los artículos 56 y 57 de la Constitución, antes citados (en adelante, "proyecto sobre el perfeccionamiento interno de los tratados» o "proyecto»).

La finalidad de este trabajo es, precisamente, analizar las disposiciones constitucionales vigentes sobre la aprobación de los tratados por el Congreso de la República del Perú, para contribuir en la determinación más clara posible de los supuestos en los que los tratados requieren de dicha aprobación, en tanto que nuestro ordenamiento interno los considera tratados solemnes o complejos, así como de aquellos en los que no la requieren, en tanto que se les considera simples o simplificados o, como los llama hoy el Reglamento del Congreso de la República, «tratados internacionales ejecutivos» ${ }^{4}$.

\section{Supuestos en los que un tratado requiere la aprobación previa del Congreso de la República}

El artículo 56 de la Constitución establece una relación de materias que, de ser reguladas a través de tratados, exigen que estos sean aprobados por el Congreso para,

\footnotetext{
4 En efecto, el artículo 92 del Reglamento del Congreso de la República es el que emplea la denominación de «tratados internacionales ejecutivos» para referirse a los tratados que no requieren de la aprobación del Congreso, a los que la doctrina llama tratados simples o simplificados.

Es importante hacer notar que, a diferencia de lo que ocurría con la ley 25397 antes citada, el Reglamento del Congreso de la República, dentro del marco de la Constitución de 1993, no establece un rango para los tratados internacionales ejecutivos. En ese sentido, en el ordenamiento jurídico peruano vigente, estos acuerdos tienen el mismo rango que aquellos que sí han sido aprobados por el Congreso.

Además, conviene recordar que el Tribunal Constitucional ha seńalado que en el Perú los tratados tienen rango de ley, con excepción de aquellos que versan sobre derechos humanos, que tienen rango constitucional (2006, fundamento 61).
} 
recién luego, considerar que el presidente de la República, en el marco del artículo 118.11 de la Constitución, ha quedado facultado para manifestar el consentimiento del Estado en obligarse por ellos 5 . Este requisito de aprobación previa no se exige, como lo reitera el primer párrafo del artículo 57 de la Constitución, cuando los tratados no versen sobre dichas materias.

Así, los tratados que el artículo 56 de la Constitución considera que requieren la aprobación previa del Congreso de la República son aquellos que:

- Versan sobre derechos humanos.

- Versan sobre soberanía, dominio o integridad del Estado.

- Versan sobre defensa nacional.

- Versan sobre obligaciones financieras del Estado.

- Crean, modifican o suprimen tributos.

- Exigen la modificación o derogación de alguna ley.

- Requieren medidas legislativas para su ejecución.

Este es un «sistema de «lista positiva» (...) plasmado también en el artículo 94(1) de la Constitución española; 53 de la Constitución francesa; 80 de la Constitución italiana; 59(2) de la Ley Fundamental de Bonn; entre otros» (Novak, 2013, p. 1046). $\mathrm{Su}$ finalidad es reducir los supuestos en los que se pueda generar duda o confusión sobre la necesidad o no de la aprobación previa del Congreso. Sin embargo, como se ha señalado líneas arriba y precisaré más adelante, en la práctica peruana se presentan interpretaciones diversas y hasta contradictorias del artículo 56 de la Constitución.

Por otro lado, el segundo párrafo del artículo 57 de la Constitución agrega un supuesto adicional en el que los tratados no solo requieren la aprobación del Congreso, sino que se exige, además, que dicha aprobación se tramite siguiendo el procedimiento que el artículo 206 de la Constitución exige para su reforma ${ }^{6}$. Dicho artículo 57, en su segundo párrafo, establece que:

Cuando el Tratado afecte disposiciones constitucionales debe ser aprobado por el mismo procedimiento que rige la reforma de la Constitución, antes de ser ratificado por el Presidente de la República.

\footnotetext{
5 El artículo 118.11 de la Constitución de 1993 establece que: «Corresponde al Presidente de la República: (...) 11. Dirigir la política exterior y las relaciones internacionales; y celebrar y ratificar tratados».

6 El artículo 206 de la Constitución señala que: «Toda reforma constitucional debe ser aprobada por el Congreso con mayoría absoluta del número legal de sus miembros, y ratificada mediante referéndum. Puede omitirse el referéndum cuando el acuerdo del Congreso se obtiene en dos legislaturas ordinarias sucesivas con una votación favorable, en cada caso, superior a los dos tercios del número legal de congresistas».
} 
En los acápites siguientes analizaré cada uno de los supuestos que, en virtud de los artículos 56 y 57, segundo párrafo, de la Constitución, exigen la aprobación de los tratados por parte del Congreso de la República antes de que el Presidente pueda manifestar el consentimiento del Estado en obligarse por ellos.

\subsection{Tratados que versen sobre derechos humanos}

La justificación para que los tratados que versen sobre derechos humanos requieran la aprobación del Congreso de la República se encuentra en: (1) la importancia de los derechos humanos para la protección de las personas; (2) el rango constitucional que el Tribunal Constitucional le reconoce a los tratados sobre derechos humanos (2006, fundamento 61); (3) los antecedentes normativos del ordenamiento jurídico peruano como, por ejemplo, lo señalado por el artículo 28 de la ley 25397 antes citado; (4) la práctica seguida en el Perú de someter los tratados sobre derechos humanos a la aprobación previa del Congreso (Novak, 2013, p. 1048); (5) la existencia de normas constitucionales en otros Estados que regulan la materia en el mismo sentido; y (6) la necesidad de contar con el compromiso político de los poderes del Estado involucrados en el proceso de celebración del tratado y con la legitimidad que de él se desprende, para garantizar su cumplimiento y su implementación en el ordenamiento jurídico interno.

Ahora bien, los tratados sobre derechos humanos no son solo aquellos por medio de los cuales se reconocen nuevos derechos, sino también aquellos que buscan dotar de mayor eficacia a los derechos ya reconocidos por el Estado. Así lo ha señalado el Tribunal Constitucional:

Los tratados en virtud de los cuales un Estado se obliga a la adopción de medidas encaminadas directamente a dotar de mayor eficacia a los derechos humanos, son tratados sobre derechos humanos, aun cuando estos no reconozcan «nuevos derechos». De hecho, muchas veces, son justamente las medidas concretas que el Estado asume internacionalmente, a través de determinados tratados complementarios, las que permiten perfilar con mayor nitidez los alcances del contenido protegido de tales derechos y, consecuentemente, las que permiten, al amparo de la Cuarta Disposición Final de la Constitución, interpretar de modo más preciso los derechos fundamentales reconocidos por ella. En otros términos, la existencia o no de un tratado sobre derechos humanos, no viene definida por un criterio formal como puede ser el análisis de si se trata de un tratado que por primera vez reconoce un derecho de ese carácter, sino por un criterio material, consistente en analizar si el tratado se ocupa directamente de un derecho humano, sea para reconocerlo por vez primera, sea para asumir obligaciones orientadas a su más eficiente protección (2011, fundamento 69).

Reconociendo lo planteado por el Tribunal Constitucional, el proyecto sobre el perfeccionamiento interno de los tratados al que antes me he referido, recoge una 
interesante relación de tratados sobre esta materia. En esa línea, se puede afirmar que un tratado versa sobre derechos humanos:

a) Cuando reconoce derechos humanos, ya sea que estén o no regulados en la Constitución Política del Perú como derechos fundamentales, o en normas internacionales de las cuales el Perú es parte (artículo 5.1):

Los derechos fundamentales recogidos en la Constitución son protegidos dentro del ámbito jurisdiccional interno; mientras que los derechos humanos son protegidos no solo en dicho ámbito, sino también en el marco de la jurisdicción internacional. En ese sentido, por más que un derecho ya esté contemplado en la Constitución como fundamental, su reconocimiento como derecho humano amplía su ámbito de protección.

Por otro lado, el hecho de que un tratado ya reconozca un derecho humano no impide que otro tratado también lo haga. Una característica del derecho internacional es que una misma norma puede estar contenida en varias fuentes a la vez. Además, hay que recordar que la jurisdicción internacional para la protección de derechos humanos no está centralizada, si bien tenemos al Sistema Interamericano de Protección de Derechos Humanos, también tenemos los mecanismos convencionales del Sistema Universal de Protección de Derechos Humanos. En esa medida, un tratado versa sobre derechos humanos al reconocer un derecho, incluso si tal derecho ya está reconocido en otro instrumento internacional.

b) Cuando amplía los alcances de aplicación o interpretación de uno o varios derechos humanos (artículo 5.2):

Los derechos humanos son inherentes a las personas, como lo es también la dignidad que esos derechos buscan proteger y cuyo desarrollo buscan garantizar $^{7}$. A lo largo de la historia de la humanidad se han ido reconociendo esos derechos, pero no siempre con el mismo alcance en su aplicación, ni tampoco en su interpretación.

Conforme evoluciona la sociedad, el reconocimiento de los derechos humanos, su forma de aplicación e interpretación también lo hacen. Sin embargo, si esos derechos están reconocidos en un tratado, su aplicación e interpretación se ve limitada por los principios de pacta sunt servanda y de buena fe. Mal harían los tribunales internacionales al pretender ampliar los alcances de aplicación o de interpretación de un derecho humano regulado en un tratado, al margen

\footnotetext{
7 Para mayores detalles sobre este tema véase: Abugattás, 2003.
} 
de las normas generales sobre la interpretación de tratados e incorrectamente escudados en normas particulares sobre la interpretación y aplicación de dichos instrumentos internacionales.

Si se considera que un derecho humano, recogido en un tratado, ha quedado desfasado frente a la evolución de la sociedad, lo correcto sería adecuarlo a través de la celebración de otro acuerdo que precise sus alcances o los nuevos criterios para su interpretación. Así, el tratado que cumpla esta función, sin lugar a dudas, versaría sobre derechos humanos y, por tanto, requeriría la aprobación previa del Congreso de la República.

c) Cuando establece la obligación de implementar medidas directamente encaminadas a dotar de mayor eficacia a los derechos humanos (artículo 5.3):

Este supuesto está en directa relación con lo afirmado por el Tribunal Constitucional, en el sentido de que: «Los tratados en virtud de los cuales un Estado se obliga a la adopción de medidas encaminadas directamente a dotar de mayor eficacia a los derechos humanos, son tratados sobre derechos humanos, aun cuando estos no reconozcan «nuevos derechos»» (2011, fundamento 69). La única precisión que se debe hacer al respecto es que este supuesto se refiere a medidas que deban tomarse tanto en el ámbito interno como en el internacional.

d) Cuando establece un sistema de protección internacional de derechos humanos o un mecanismo de cooperación que ayude a garantizar la efectividad de derechos humanos o a sancionar su violación (artículo 5.4):

Una vez más, estamos ante un supuesto que va en la línea de lo establecido por el Tribunal Constitucional, en el sentido de que debe considerarse como tratado que versa sobre derechos humanos al que recoge la obligación de tomar medidas que buscan dotar de «mayor eficacia» a esos derechos (2011, fundamento 69).

El establecimiento de un sistema internacional de protección de derechos humanos o de un mecanismo de cooperación que ayude a garantizar la eficacia de dichos derechos o sancionar su violación, se materializa, por ejemplo, a través de la creación de un tribunal internacional, de un órgano de una organización internacional, un comité o una institución internacional que busque tales objetivos.

e) Cuando reconoce la competencia contenciosa o consultiva de un tribunal, corte, comité o similar, de carácter internacional, en materia de derechos humanos (artículo 5.5):

A diferencia del supuesto anterior, que se refiere al establecimiento o creación de instituciones internacionales destinadas a garantizar la efectividad de los derechos humanos o sancionar su violación, este contempla los casos en los que se reco- 
noce la competencia contenciosa o consultiva de tales instituciones, con miras a garantizar la "mayor eficacia» de los derechos humanos. Por ello, en el marco de lo señalado por el Tribunal Constitucional, el tratado por el que se haga este reconocimiento versaría sobre derechos humanos (2011, fundamento 69).

f) Cuando versa sobre otras materias, distintas de las señaladas en el presente artículo, pero que estén referidas a derechos humanos (articulo 5.6):

Al regular la aprobación de tratados por el Congreso de la República como condición para que el Presidente quede facultado para manifestar el consentimiento del Estado en obligarse por ellos, no es posible prever todas las situaciones que pudieran presentarse en las relaciones internacionales.

Por ello, cualquier regulación que pretenda establecer una lista de supuestos en los que se requiere la referida aprobación legislativa, debe ser lo suficientemente flexible para facilitar el trabajo del Congreso de la República y del Ministerio de Relaciones Exteriores; claro está, siempre que esa flexibilidad se enmarque en los parámetros constitucionales.

Así, debe interpretarse que esta lista de supuestos es enumerativa y no taxativa. En esa medida, estarían incluidos como tratados que versan sobre derechos humanos, por ejemplo, aquellos referidos al derecho internacional humanitario, al asilo diplomático o al asilo político, al derecho penal internacional, entre otros.

\subsection{Tratados que versen sobre soberanía, dominio o integridad del Estado}

La referencia que hace el artículo 56.2 de la Constitución a la «soberanía», puede llevar a confusión al momento de interpretar esta disposición. Se considera que el poder político, del que es titular el pueblo y que ejercen sus gobernantes, es soberano; esto significa que dicho poder no reconoce poderes superiores, sino solo iguales ${ }^{8}$. De aquí se deriva el principio de igualdad soberana de los Estados.

En ese sentido, toda decisión de un Estado es, por naturaleza, una decisión soberana. Por ello, si a esa idea le sumamos que un tratado recoge el acuerdo de voluntades soberanas de los Estados, el artículo 56.2 de la Constitución nos debería llevar a la conclusión de que todos los tratados celebrados por el Estado versan sobre soberanía, lo que, desde luego, no es correcto.

\footnotetext{
8 Debe entenderse, por cierto, que el ejercicio del poder político soberano no es ilimitado, sino que está enmarcado por las normas constitucionales del Estado y por el conjunto de normas internacionales aceptadas por dicho Estado y, por tanto, obligatorias para él. Para profundizar sobre el estudio de esta materia véase: Duverger, 1970.
} 
La frase «soberanía, dominio o integridad del Estado» recogida en la Constitución debe interpretarse en otro sentido. Debe considerarse que la «soberanía», en el marco del artículo 56.2, se refiere al conjunto de competencias que ejercen las diferentes instancias del gobierno del Estado, es decir, los organismos estatales: ejecutivo, legislativo, judicial, organismos constitucionales, gobiernos regionales, gobiernos locales, entre otros.

Así, de acuerdo con el artículo 56.2 de la Constitución, un tratado versa sobre soberanía cuando regula el ejercicio de las competencias soberanas del Estado o cuando se utiliza para cederlas o renunciar a ellas. Sin embargo, no serán tratados que versan sobre soberanía aquellos en los que simplemente se evidencie el ejercicio por parte del Estado de alguna de sus competencias soberanas.

Por otro lado, el dominio, en el contexto del artículo 56.2 de la Constitución, es el poder que tiene el Estado para aplicar sus normas y controlar todos los elementos, materiales e inmateriales, que abarca su territorio: suelo, subsuelo, mar adyacente, espacio aéreo, espectro electromagnético, entre otros elementos ya descubiertos o por descubrir ${ }^{9}$. Así, un tratado versa sobre «dominio» cuando regula el ejercicio del poder del Estado sobre los elementos de su territorio.

Ahora bien, la integridad del Estado en el marco del artículo 56.2 de la Constitución, debe entenderse como «integridad territorial». En ese sentido, un tratado versa sobre integridad del Estado cuando en él se regula cualquier aspecto vinculado a la conservación del conjunto del territorio del Estado.

Así entendida la frase «soberanía, dominio o integridad del Estado», serían ejemplos de tratados que versan sobre esta materia, siguiendo la línea de lo establecido en el proyecto sobre el perfeccionamiento interno de los tratados, entre otros:

a) Aquellos por los que «se cede a otro sujeto de derecho internacional, institución internacional o actor internacional, alguna de las competencias soberanas del Estado; como las de juzgar, legislar, realizar labores de fiscalización o control, u otras similares» (artículo 6.1).

b) Aquellos por los que «se renuncia a alguna de las competencias soberanas del Estado, como las señaladas en el [párrafo] anterior, en favor de otro sujeto de Derecho internacional, institución internacional o actor internacional) (articulo 6.2, modificación propia).

\footnotetext{
9 Se puede encontrar un estudio muy interesante referido al dominio del Estado sobre su territorio en: Jellinek, 2014, pp. 368-378.
} 
c) Aquellos por los que se regule el ejercicio de alguna competencia soberana del Estado, como las señaladas líneas arriba.

Este supuesto no está contemplado en el proyecto sobre el perfeccionamiento interno de los tratados; sin embargo, estimo que debiera estar considerado en la lista que el artículo 6 de dicho proyecto propone como supuestos de tratados que versan sobre soberanía, dominio o integridad del Estado.

d) Aquellos por los que se otorgan privilegios o inmunidades a personas, sean o no funcionarios internacionales; a organizaciones internacionales; a representaciones diplomáticas o consulares; así como a instituciones; y siempre que esos privilegios o inmunidades no les sean ya aplicables en virtud de otros acuerdos internacionales de los que el Perú sea Estado parte.

Este supuesto está contemplado, con una redacción distinta, en el proyecto sobre el perfeccionamiento interno de los tratados ${ }^{10}$. Guarda relación con la soberanía del Estado, en tanto que el otorgamiento de privilegios o inmunidades implica que el Estado renuncia a ciertas competencias soberanas, que no podrá ejercer en relación con quienes gocen de las prerrogativas concedidas.

Sin embargo, estimo que se debe emplear la redacción que propongo y no la del texto del proyecto, que hace referencia al otorgamiento de privilegios o inmunidades «a nacionales de otros Estados». Esto, ya que se debe considerar que tales prerrogativas se pueden otorgar a personas al margen de su nacionalidad, en atención, por ejemplo, a una labor concreta que vayan a realizar en el Estado. Por ello, es más acertada la referencia «a personas», en términos generales. Además, también se pueden otorgar privilegios o inmunidades a organizaciones internacionales, a representaciones diplomáticas o consulares, así como a cualquier institución, por lo que estos casos debieran también estar contemplados en el proyecto.

Por otro lado, cuando se establece «que esos privilegios o inmunidades no les sean ya aplicables a esas personas en virtud de otros acuerdos internacionales de los que el Perú sea Estado parte», se hace con la finalidad de no someter tratados innecesariamente a la aprobación del Congreso de la República. Sin embargo, esta disposición debe interpretarse con cuidado.

Si un tratado establece, por ejemplo, privilegios ya contenidos en un tratado previo del que el Perú es Estado parte, pero lo hace señalándolos o determinán-

\footnotetext{
${ }^{10} \mathrm{El}$ artículo 6.3 del proyecto está redactado de la siguiente manera: «Cuando se otorgan privilegios o inmunidades a nacionales de otros Estados, sean o no funcionarios internacionales, y siempre que esos privilegios o inmunidades no les sean ya aplicables a esas personas en virtud de otros acuerdos internacionales de los que el Perú sea Estado parte».
} 
dolos de manera expresa, o simplemente remitiéndose a una lista de privilegios ya contemplados en un tratado previo, considero que debe exigirse la aprobación previa del Congreso. Esto, en la medida en que la terminación del tratado previo no afectará el goce de los privilegios contenidos de manera expresa en el tratado posterior o a los que se hace referencia con una simple remisión al tratado previo (al margen de que este permanezca o no en vigor). En otras palabras, el tratado estaría estableciendo una nueva relación jurídica que requeriría la aprobación del Congreso de la República.

Sin embargo, si un tratado establece, por ejemplo, privilegios ya contenidos en un tratado previo del que el Perú es Estado parte, pero lo hace «en virtud» de la aplicación de ese tratado previo, considero que el tratado posterior ya no requeriría la aprobación del Congreso de la República, pues el privilegio lo otorga, en estricto, el tratado anterior, que puede presumirse que ya pasó por la aprobación del Congreso.

En este último supuesto, la terminación del tratado previo sí afectaría el goce de los privilegios a los que se refiere el tratado posterior. Si los privilegios benefician a una persona «en virtud» de un tratado previo, el goce de esos privilegios guarda relación directa con la vigencia de ese tratado; así, esa persona goza de esos privilegios solo en la medida en que permanezca en vigor ese tratado previo. El tratado posterior no estaría estableciendo una nueva relación jurídica, sino simplemente recordando que existe una relación jurídica anterior que es de aplicación en el contexto de ese tratado posterior.

e) Aquellos por los que se afecta, en favor o en contra del Estado peruano, alguna de sus fronteras o alguno de los derechos soberanos que ejerce sobre cualquiera de los elementos de su territorio.

Este supuesto también está contemplado en el proyecto sobre el perfeccionamiento interno de los tratados, pero con una redacción distinta ${ }^{11}$. La referencia a la afectación de alguna de sus fronteras guarda relación con la integridad del Estado, en los términos antes señalados, e incluye supuestos como el de los tratados de límites. Por otro lado, la referencia a la afectación de los derechos soberanos que ejerce sobre cualquiera de los elementos de su territorio, guarda relación con el dominio del Estado, según se ha explicado.

\footnotetext{
${ }^{11} \mathrm{El}$ artículo 6.4 del proyecto está redactado de la siguiente manera: «Cuando se afecta, en favor o en contra del Estado peruano, alguna de las fronteras o alguno de los derechos soberanos que ejerce sobre el suelo, subsuelo, mar adyacente a sus costas y el espacio aéreo que los cubre».
} 
La afectación de las fronteras del Estado en su contra, por su gravedad, es evidente que requiere la aprobación legislativa. Por otro lado, la afectación de las fronteras del Estado en su favor, podría traer consecuencias futuras, por lo que el tratado que materialice esta afectación debe ser aprobado por el Congreso de la República, que deberá valorar esas posibles consecuencias.

Ahora bien, en cuanto a la redacción, el proyecto hace referencia a los derechos soberanos que el Estado ejerce «sobre el suelo, subsuelo, mar adyacente a sus costas y el espacio aéreo que los cubre». Sin embargo, es más acertado referirse a los «derechos soberanos que ejerce sobre cualquiera de los elementos de su territorio", ya que, de esa manera, no solo se considerarían los elementos precisados en el proyecto, sino cualesquiera otros que existan o que se puedan descubrir, según se ha explicado líneas arriba.

f) Aquellos que se refieren al uso o usufructo de cualquiera de los elementos del territorio del Estado.

Este supuesto está contemplado, con otra redacción, en el proyecto sobre el perfeccionamiento interno de los tratados ${ }^{12}$. Guarda relación con el concepto de dominio del Estado.

De manera similar al caso anterior, el texto del proyecto hace referencia al territorio, al mar y al espacio aéreo que los cubre; sin embargo, por las razones explicadas al referirme al caso anterior, considero más acertado referirse al uso o usufructo «de cualquiera de los elementos del territorio del Estado».

En el marco de este supuesto estarían, por ejemplo, los tratados que se refieran a la explotación de minerales, de recursos marinos o de cualquier otro recurso natural, así como los tratados referidos a la protección del medio ambiente, al uso del espectro electromagnético, a la utilización del espacio aéreo, entre muchos otros supuestos.

Es importante recordar que los supuestos señalados son solo algunos ejemplos de tratados que versan sobre soberanía, dominio o integridad del Estado. Como indiqué en el acápite anterior, no es posible prever todas las situaciones que se pueden presentar en las relaciones internacionales.

Esto lo reconoce también el proyecto sobre el perfeccionamiento interno de los tratados que, al regular los supuestos en los que un acuerdo versa sobre soberanía, dominio o integridad del Estado, recoge en su artículo 6.6 una cláusula de apertura a otros supuestos que no hayan sido contemplados, pero que se refieran a dichas

\footnotetext{
${ }^{12}$ El artículo 6.5 del proyecto está redactado de la siguiente manera: «Cuando se refiere al uso o usufructo del territorio, del mar adyacente a sus costas o del espacio aéreo que los cubre».
} 
materias ${ }^{13}$. De esta manera, se garantiza que, dentro de los parámetros constitucionales, la regulación que propone sea lo suficientemente flexible como para facilitar el trabajo del Congreso de la República y del Ministerio de Relaciones Exteriores.

Sin embargo, la redacción del mencionado artículo 6.6, hace referencia al dominio que el Estado «ejerce sobre sus nacionales y sobre extranjeros que se encuentran en su territorio». De acuerdo con lo explicado líneas arriba, en el marco del artículo 56.2 de la Constitución, dominio debe entenderse como el poder que se ejerce sobre todos los elementos que integran el territorio del Estado; sin pretender negar, con esto, el hecho de que ese dominio se materialice, se concrete o se ejerza a través de las personas, en tanto que el Estado es una «entidad jurídica». Por ello, considero que en dicho artículo debe eliminarse esa referencia.

\subsection{Tratados que versen sobre defensa nacional}

Para algunos, la exigencia de que un tratado que verse sobre defensa nacional pase por la aprobación del Congreso de la República, podría parecer inadecuada; los temas vinculados a la defensa del Estado, en algunos casos, son reservados, por lo que requerir la aprobación legislativa podría entenderse, por algunos, como un riesgo que puede afectar la reserva con la que dichos temas deben ser manejados.

Sin embargo, la división de poderes propia de un Estado de derecho implica la existencia de una serie de controles entre las funciones ejecutiva, legislativa y judicial, de modo tal que se garantice el imperio de la ley. La aprobación de tratados que versen sobre defensa nacional es un mecanismo que le permite al Congreso controlar las acciones del ejecutivo en un tema de vital importancia para el Estado. Así, si queremos vivir en un Estado de derecho, en el que hay división de poderes y controles entre ellos, no podríamos oponernos a la aprobación de tratados que versen sobre defensa nacional, considerando, además, que el Congreso puede emplear una serie de mecanismos para garantizar la reserva de los temas que así lo requieran.

Ahora bien,

[...] la defensa nacional suele ser entendida como la facultad del Estado de asegurar su integridad por la vía convencional o armada. La defensa armada puede revestir forma activa o pasiva. Por la primera, el Estado actúa contra quien intente desmembrarlo, intervenirlo o afectar en alguna forma su territorio. Por la segunda, se adoptan precauciones ante un posible conflicto armado, como son: tener un ejército perma-

\footnotetext{
${ }^{13}$ Dicho artículo establece que un tratado versa sobre soberanía, dominio o integridad del Estado: "Cuando versa sobre otras materias, distintas de las señaladas en los numerales anteriores, referidas a la soberanía del Estado, al dominio que ejerce sobre sus nacionales y sobre extranjeros que se encuentran en su territorio o a la integridad del Estado».
} 
nente y una organización de reserva; instruir a sus ciudadanos para la defensa nacional mediante el servicio militar; construir fortificaciones y vías estratégicas; almacenar pertrechos y municiones; u organizando, en fin, todo sistema técnico y económico que le permita poner en acción sus fuerzas y su espíritu en el momento del peligro (Novak, 2013, p. 1050).

En este orden de ideas, todo tratado por el que se busque garantizar la integridad del Estado, versa sobre defensa nacional. Así, por ejemplo, siguiendo la línea de lo establecido en el proyecto sobre el perfeccionamiento interno de los tratados, podrían considerarse tratados que versan sobre defensa nacional, entre otros:

a) Aquellos por los que "se declara o se da por terminado un conflicto armado internacional, en los términos establecidos en las normas de Derecho internacional humanitario» (artículo 7.1).

Este supuesto guarda relación con el artículo 118.16 de la Constitución, que establece que: "Corresponde al Presidente de la República: [...] Declarar la guerra y firmar la paz, con autorización del Congreso».

b) Aquellos por los que se entrega a otro sujeto de Derecho internacional, institución o actor internacional, o se recibe de alguno de ellos, en virtud de cualquier acto de disposición de la propiedad, armas, maquinaria, equipos, uniformes o similares, empleados por las fuerzas armadas.

Este supuesto, con otra redacción, está recogido en el proyecto sobre el perfeccionamiento interno de los tratados ${ }^{14}$. En el artículo 7.2 de ese proyecto se hace referencia a la compra, la venta, la donación, el préstamo y la puesta a disposición; sin embargo, esos no son los únicos actos por medio de los cuales se puede disponer de la propiedad. Por otro lado, en dicho artículo también se hace referencia a los sujetos de derecho internacional, instituciones «internacionales» y actores internacionales; sin embargo, considerando que se busca incluir a Estados, dependencias internas de los Estados, organizaciones internacionales, empresas públicas o privadas vinculadas con el rubro de la defensa o la tecnología, entre otros, la calificación de las instituciones como «internacionales» debe eliminarse. Por ello, considero más acertada la redacción propuesta, que aquella utilizada en el artículo 7.2 del proyecto.

c) Aquellos por los que se entrega a otro sujeto de Derecho internacional, institución o actor internacional, o se recibe de alguno de ellos, en virtud de cualquier acto de

\footnotetext{
${ }^{14}$ El artículo 7.2 del proyecto está redactado de la siguiente manera: «Cuando se compra, se vende o se dona a otro sujeto de derecho internacional, institución internacional o actor internacional, o se recibe de ellos por donación, préstamo o puesta a disposición, armas, maquinaria, equipos, uniformes o similares, empleados por las fuerzas armadas».
} 
disposición de la propiedad, tecnología, satélites u otros similares, para ser empleados de manera exclusiva por las fuerzas armadas o de manera compartida con otras instituciones, ya sea que su control esté o no a cargo de las fuerzas armadas.

Como en el caso anterior, este supuesto también está recogido con otra redacción en el proyecto sobre el perfeccionamiento interno de los tratados ${ }^{15}$. Sin embargo, por las mismas razones explicadas en el caso anterior, considero más acertada la redacción propuesta, que aquella utilizada en el artículo 7.3 del proyecto.

d) Aquellos por los que se acuerda una transferencia de tecnología en materia de defensa nacional.

Este supuesto, con otra redacción, está recogido en el proyecto sobre el perfeccionamiento interno de los tratados ${ }^{16}$. Sin embargo, considero que la referencia que hace el artículo 7.4 de dicho proyecto a los sujetos, instituciones o actores es innecesaria; por ello, considero más acertada la redacción que aquí se propone.

e) Aquellos por los que se acuerda disponer, con cualquier finalidad, del personal o de los equipos de las fuerzas armadas.

Este supuesto está recogido en el artículo 7.5 del proyecto sobre el perfeccionamiento interno de los tratados, con una redacción muy similar ${ }^{17}$. Sin embargo, considero más precisa la redacción que aquí se propone.

Es importante recordar que los supuestos señalados son solo algunos ejemplos de tratados que versan sobre defensa nacional. Como indiqué en los acápites anteriores, no es posible prever todas las situaciones que se pueden presentar en las relaciones internacionales.

Esto lo reconoce también el proyecto sobre el perfeccionamiento interno de los tratados que, al regular los supuestos en los que un acuerdo versa sobre defensa nacional, recoge en su artículo 7.6 una cláusula de apertura a otros supuestos que no

\footnotetext{
${ }^{15}$ El artículo 7.3 del proyecto está redactado de la siguiente manera: «Cuando se compra, se vende o se dona a otro sujeto de derecho internacional, institución internacional o actor internacional, o se recibe de ellos por donación, préstamo o puesta a disposición, equipos de tecnología avanzada, satélites u otros similares, para ser empleados de manera exclusiva por las fuerzas armadas o de manera compartida con otras instituciones del Estado, ya sea que su control esté o no a cargo de las fuerzas armadas».

${ }^{16} \mathrm{El}$ artículo 7.4 del proyecto está redactado de la siguiente manera: «Cuando se establece una transferencia de tecnología en materia de defensa nacional, entre sujetos de derecho internacional, instituciones internacionales o actores internacionales, indistintamente».

${ }^{17} \mathrm{El}$ artículo 7.5 del proyecto está redactado de la siguiente manera: «Cuando se dispone de personal o equipos de las fuerzas armadas, cualquiera que fuere el fin».
} 
hayan sido contemplados, pero que se refieran a dichas materias ${ }^{18}$. De esta manera, se garantiza que, dentro de los parámetros constitucionales, la regulación que propone sea lo suficientemente flexible como para facilitar el trabajo del Congreso de la República y del Ministerio de Relaciones Exteriores.

En materia de tratados que versan sobre defensa nacional, en efecto, se pueden presentar muchos otros casos, siendo imposible que una norma los pretenda contemplar todos. Así, por ejemplo, también versan sobre defensa nacional «los tratados de seguridad colectiva; los tratados de alianza defensiva, los de no agresión o neutralidad; y los que establezcan organizaciones internacionales de cooperación militar» (Novak, 2013, p. 1050). También versan sobre defensa nacional los tratados por los que se autorice el ingreso de militares extranjeros al territorio nacional, ya que el ingreso de tropa extranjera puede poner en riesgo las labores de aseguramiento de la integridad del Estado ${ }^{19}$.

\subsection{Tratados que versen sobre obligaciones financieras del Estado}

Se debe tomar en consideración que:

[...] el artículo 102, incisos 4 y 5 del texto constitucional consagra como atribuciones del Congreso aprobar el presupuesto y la cuenta general de la República, así como autorizar empréstitos, conforme a la Constitución. En este sentido, resulta lógico que el artículo 56 del mismo texto normativo obligue a que aquellos tratados que impliquen una obligación financiera del Estado sean aprobados por el Congreso antes de su ratificación presidencial, debiendo entenderse como comprendidos en esta categoría, todos aquellos tratados que versen sobre operaciones de endeudamiento interno y externo del Estado (Novak, 2013, p. 1050).

En la sentencia emitida en el marco del proceso de inconstitucionalidad que se inició contra el Acuerdo de Libre Comercio Perú - Chile, el Tribunal Constitucional (5 de febrero de 2010), señaló que:

La determinación de lo que deba entenderse por «obligación financiera del Estado» es relevante para establecer si el ALC PERÚ - CHILE se inserta dentro de lo previsto en el artículo 56 inciso 4 (sic.) de la Constitución. A juicio de este Colegiado, y a efectos de la interpretación de dicho artículo, se entiende que un tratado genera obligaciones financieras cuando estas exigen al Estado erogaciones económicas internas o externas a fin de implementar su aplicación. [...] (fundamento 45).

\footnotetext{
${ }^{18}$ El artículo 7.6 del proyecto está redactado de la siguiente manera: «Cuando versa sobre otras materias, distintas de las seńaladas en los numerales anteriores, pero referidas a defensa nacional o bajo el control del Ministerio de Defensa».

${ }^{19}$ Recuérdese que el artículo 102.8 de la Constitución establece que: «Son atribuciones del Congreso: [...] Prestar consentimiento para el ingreso de tropas extranjeras en el territorio de la República».
} 
En este orden de ideas, siguiendo lo establecido en el proyecto sobre el perfeccionamiento interno de los tratados, se pueden considerar como ejemplos de tratados que versan sobre obligaciones financieras del Estado, entre otros:

a) Aquellos por los que "se contrata o se autoriza la contratación de deuda externa, así como cuando se establece la posibilidad de endeudamiento externo" (artículo 8.1).

Un tratado puede ser el medio a través del cual se contrata deuda externa; además, puede ser el instrumento que autoriza al Ejecutivo a realizar una operación «cierta» de contratación de deuda externa, que se materializaría en un instrumento distinto y posterior.

Sin embargo, en la práctica peruana se han celebrado tratados en los que una fuente cooperante ofrece una donación al Estado, siempre que cumpla con algunas condiciones, estableciéndose que, en caso de que tales condiciones no sean cumplidas, el Estado peruano podrá acceder al monto ofrecido, pero ya no a través de una donación, sino de un préstamo. Este es el caso, por ejemplo, de varios acuerdos de cooperación celebrados entre Alemania y el Perú ${ }^{20}$. En estos casos, el tratado no es el instrumento por el que se contrata la deuda ni tampoco, el que autoriza una operación cierta de contratación de deuda, sino que es un instrumento en el que se establece la posibilidad de endeudamiento externo.

La manifestación del consentimiento del Estado en obligarse por un tratado que establece la posibilidad de acceder a un endeudamiento externo, autoriza al Ejecutivo para que, de considerarlo adecuado para los intereses nacionales, celebre el contrato de deuda al que se refiere el tratado. Si bien no hay certeza sobre la celebración de ese contrato de endeudamiento, la posibilidad de celebrarlo quedaría autorizada por el tratado. Por esa razón, estos acuerdos se pueden calificar como tratados que versan sobre obligaciones financieras del Estado y, en esa medida, requieren la aprobación previa del Congreso.

b) Aquellos por los que se «establece la obligación de pago en dinero o especie, en una o varias cuotas, sea cual fuere el concepto de esas cuotas, en favor de un sujeto de Derecho internacional, institución internacional o actor internacional» (artículo 8.2).

\footnotetext{
${ }^{20}$ Por ejemplo: «Acuerdo referido al Programa de Segunda Generación de Reformas del Sector Saneamiento entre la República Federal de Alemania y la República del Perú» (celebrado en el año 2016); «Acuerdo entre la República del Perú y la República Federal de Alemania sobre Cooperación Financiera 2015 referente al proyecto «Transporte Urbano Sostenible en Ciudades Seleccionadas del Perú»» (celebrado en el ańo 2015); «Convenio entre el Gobierno de la República Federal de Alemania y el Gobierno de la República del Perú sobre Cooperación Financiera 2009» (que, pese al nombre, fue celebrado en el ańo 2011); «Acuerdo sobre Cooperación Financiera entre el Gobierno de la República Federal de Alemania y el Gobierno de la República del Perú, relativo al Proyecto "Programa de Reformas en el Sector Saneamiento"» (celebrado en el ańo 2009); entre otros.
} 
Este sería el caso de los tratados que, sin referirse a la contratación de deuda externa, establecen, por la razón que fuere, la obligación de realizar erogaciones económicas en dinero o en especie. Este supuesto abarcaría, por ejemplo, a tratados en los que el Estado se compromete a donar una suma de dinero o un producto determinado en el marco de un proyecto de cooperación internacional.

c) Aquellos por los que se "establece la incorporación del Estado en una organización internacional en la que tiene la obligación de pagar cuotas, en dinero o en especie; ya sea que el tratado contemple esta obligación o que se derive de las normas internas de dicha organización internacional» (articulo 8.3).

El pago de cuotas a las organizaciones internacionales es, por regla general, la forma en la que estas financian las actividades que realizan. Lo usual, es que la incorporación de un Estado a una organización internacional, venga acompañada de la obligación de pagar cuotas con este fin. Evidentemente, estos pagos se traducen en una obligación financiera del Estado.

Ahora bien, hay casos excepcionales en los que el pago de cuotas en una organización internacional no es obligatorio, sino voluntario. Por ejemplo, el Instituto Global para el Crecimiento Verde, organización internacional de la que el Perú es miembro y que promueve el desarrollo de los Estados a través de medios que garanticen la sostenibilidad ambiental, establece en su tratado constitutivo que se financiará, entre otros, a través de contribuciones "voluntarias» de sus miembros, estableciendo dos tipos de miembros: los «contribuyentes» y los "participantes» ${ }^{21}$.

En estos casos, la manifestación del consentimiento del Estado en obligarse por el tratado constitutivo de la organización, que establece la posibilidad de realizar aportes voluntarios, autoriza al Ejecutivo para que si lo considera adecuado para los intereses nacionales, realice dichas contribuciones financieras. Si bien no hay obligación de realizar erogaciones económicas, la posibilidad de hacerlas quedaría autorizada por el tratado. Por esa razón, estos acuerdos se pueden calificar como tratados que versan sobre obligaciones financieras del Estado y, en esa medida, requieren la aprobación previa del Congreso.

Finalmente, también se pueden presentar casos en los que el tratado constitutivo de una organización internacional no establezca la obligación de pago de cuotas, pero las normas internas de dicha organización sí lo hagan. Este es el caso del Comité de Sanidad Vegetal del Cono Sur, organización internacional de la que

\footnotetext{
${ }^{21} \mathrm{Al}$ respecto, véase por ejemplo lo señalado en los artículos 3 y 12 del tratado constitutivo del Global Green Growth Institute.
} 
el Perú es miembro ${ }^{22}$. El tratado constitutivo de dicha organización no establece la obligación del pago de cuotas; sin embargo, a través de la resolución 113/28$11 \mathrm{M}$, del Consejo de Ministros de la organización, se aprobó la solicitud de adhesión del Perú, estableciéndose el monto del aporte anual que tiene que realizar como miembro de la organización ${ }^{23}$.

En estos casos, «la implementación del tratado constitutivo», que permitiría la participación efectiva del Perú como Estado miembro de la organización, «exige una erogación económica externa» determinada por las normas internas de la organización. Por ello, de acuerdo con lo dispuesto por el Tribunal Constitucional en la sentencia citada líneas arriba, se debe considerar que estos tratados constitutivos versan sobre obligaciones financieras del Estado y, por tanto, requieren la aprobación previa el Congreso de la República.

d) Aquellos por los que se uestablece el compromiso de cubrir costos vinculados a la realización en el Perú o en el extranjero, de una actividad internacional, como conferencias, cumbres, reuniones o similares» (artículo 8.4).

El crecimiento económico del Perú registrado en los últimos años, además de su céntrica ubicación en América del sur, han generado que el país se convierta en una sede atractiva para la realización de varias actividades internacionales, como cumbres de países, reuniones de foros comerciales, conferencias internacionales sobre diversos temas, entre otras.

Ahora bien, la realización en el Perú de muchas de estas actividades se acuerda en tratados en los que el Estado asume una serie de obligaciones financieras que, según cada caso, varían y podrían abarcar: gastos de trasporte, gastos de alojamiento, alquiler de locales, compra de equipos, gastos por servicios de alimentación, gastos para la compra de souvenirs, pagos por el desaduanaje de bienes que ingresan al país con motivo de la actividad, pagos de personal, entre muchos otros.

\footnotetext{
22 De acuerdo con el artículo 1 del tratado constitutivo del Comité de Sanidad Vegetal del Cono Sur, su objetivo principal es «coordinar e incrementar la capacidad regional de prevenir, disminuir y evitar los impactos y riegos de los problemas que afectan a la producción y comercialización de los productos agrícolas y forestales de la región, tomando en cuenta la situación fitosanitaria alcanzada, el desarrollo económico sostenido, la salud humana y la protección del medio ambiente».

${ }^{23}$ En el punto 3 de dicho instrumento normativo interno de la organización, se resuelve: «Establecer un valor de US\$ 55,900 [...] como aporte anual de Perú, de los cuales US\$ 45,900 corresponderán a Aportes Anuales (para solventar los Planes de Trabajo derivados de los Lineamientos del COSAVE) y US\$10,000 a Aportes Exclusivos (destinados a la participación de expertos de la región en las reuniones realizadas por la Convención Internacional de Protección Fitosanitaria y en la organización de reuniones internacionales de expertos para el desarrollo de normas internacionales de interés regional). Dicho aporte se efectivizará a través de los mecanismos instrumentados en el Convenio IICA-COSAVE».
} 
En ese sentido, los tratados en los que se acuerde la realización de estas actividades y que establezcan la obligación del Estado de realizar erogaciones económicas internas o externas para su implementación, son tratados que versan sobre obligaciones financieras del Estado y, por tanto, requieren la aprobación previa del Congreso.

Una vez más, es importante recordar que los supuestos señalados son solo algunos ejemplos de tratados que versan sobre obligaciones financieras del Estado. Como indiqué en los acápites anteriores, no es posible prever todas las situaciones que se pueden presentar en las relaciones internacionales.

Esto lo reconoce también el proyecto sobre el perfeccionamiento interno de los tratados que, al regular los supuestos en los que un acuerdo versa sobre obligaciones financieras del Estado, recoge en su artículo 8.5 una cláusula de apertura a otros supuestos que no hayan sido contemplados, pero que se refieran a dichas materias ${ }^{24}$. De esta manera, se garantiza que, dentro de los parámetros constitucionales, la regulación que propone sea lo suficientemente flexible como para facilitar el trabajo del Congreso de la República y del Ministerio de Relaciones Exteriores.

Ahora bien, en atención a la forma en que el Estado peruano suele establecer el contenido de los tratados que celebra, considero necesario adecuar el texto de la cláusula de apertura contenida en el artículo 8.5 del citado proyecto, para que quede redactado de manera más precisa, estableciendo que un tratado versa sobre obligaciones financieras: cuando versa sobre otras materias, distintas de las señaladas en los numerales anteriores, pero que generan «directa o indirectamente una o más obligaciones financieras».

Por otro lado, lo cierto es que «tal como está redactado el artículo 56 literal d) de la Constitución resulta demasiado amplio» (Novak, 2013, p. 1050). Así, la exigencia de aprobación legislativa de este tipo de tratados que, como he señalado ya, suele tomar bastante tiempo, puede obstaculizar o dificultar el logro de los objetivos de la política exterior peruana. Por ello, para evitar que la aplicación de este artículo resulte perjudicial para los intereses nacionales, se hace necesario el establecimiento de una relación de supuestos en los que, pese a existir, en estricto, una obligación financiera, el legislador no considerará que el tratado versa sobre obligaciones financieras del Estado.

El artículo 9 del proyecto sobre el perfeccionamiento interno de los tratados, recogiendo esta preocupación, establece tres supuestos en los que «no se considera que un tratado versa sobre obligaciones financieras del Estados peruano»:

\footnotetext{
${ }^{24}$ El artículo 8.5 del proyecto está redactado de la siguiente manera: «Cuando versa sobre otras materias, distintas de las seńaladas en los numerales anteriores, pero que generan obligación financiera».
} 
a) "Cuando el cumplimiento de la obligación en su totalidad se hace con cargo al presupuesto aprobado del sector o de la entidad responsable de la ejecución del tratado, en un único ejercicio presupuestal» (articulo 9.1).

En algunas ocasiones, la erogación económica que exige un tratado se hace con cargo al presupuesto que el sector que ejecuta el acuerdo tiene ya aprobado para el ejercicio presupuestal correspondiente a la fecha en la que se debe cumplir la totalidad de la obligación internacional. Así, si en atención al artículo 102.4 de la Constitución el Congreso de la República ya aprobó el presupuesto de ese sector, el cumplimiento del tratado se constituiría en un mecanismo de ejecución de ese presupuesto.

Si bien, en estricto, el tratado versa sobre una obligación financiera del Estado, se puede interpretar que esta obligación, al cumplirse con cargo al presupuesto ya aprobado por el Congreso, no requeriría una nueva aprobación legislativa.

Ahora bien, hay acuerdos que generan obligaciones financieras para el Estado que se deben pagar en varias cuotas. Si una o más de esas cuotas se pagan con cargo al presupuesto que el sector que cumple con el tratado ya tiene aprobado por el Congreso de la República para el ejercicio presupuestal correspondiente a las fechas en las que se hacen esos pagos, pero las restantes cuotas se pagarán con cargo al presupuesto de ese sector correspondiente a ejercicios posteriores, el tratado requeriría la aprobación del Congreso de la República.

En el caso explicado en el párrafo anterior, las erogaciones económicas pendientes se deberán realizar con cargo al presupuesto del sector, pero correspondiente a ejercicios anuales posteriores, que aún no han sido aprobados por el Congreso de la República. Por esta razón, al proyectarse cargos a presupuestos aún no aprobados por el legislativo, el tratado versará sobre obligaciones financieras y requerirá la aprobación del Congreso.

b) "Cuando conlleva la entrega de dinero o especies; la cesión o arrendamiento de inmuebles; la contratación o puesta a disposición de personal; la realización de trámites; la prestación de servicios; el pago de tributos; el pago de remuneraciones; $u$ otras obligaciones similares, como contrapartida, en los casos de acuerdos de cooperación no reembolsable» (artículo 9.2).

En varios acuerdos de cooperación no reembolsable se pacta que, junto a los recursos que ingresan al Estado por esa vía, el Perú se compromete a asumir una serie de obligaciones financieras o a realizar actividades que generan este tipo de obligaciones. 
En estricto, entonces, este tipo de tratados contienen obligaciones financieras para el Estado. Sin embargo, someterlos al trámite de aprobación del Congreso de la República puede generar que el Estado pierda la oportunidad de recibir esa cooperación internacional no reembolsable, lo que tendría enormes efectos negativos para la sociedad en su conjunto. Por ello, se propone considerar que estos tratados no versan sobre obligaciones financieras del Estado y, por tanto, no requieren la aprobación previa del Congreso.

c) "Cuando implica la entrega de dinero o especies; la cesión o arrendamiento de inmuebles; la contratación o puesta a disposición de personal; la realización de trámites; la prestación de servicios; el pago de tributos; el pago de remuneraciones; $u$ otras obligaciones similares, en el marco de la ejecución de proyectos derivados de acuerdos de cooperación internacional en los que el ente cooperante otorga al Perú, en calidad de donación o contribución, una suma de dinero o especies» (artículo 9.3).

Este supuesto es muy similar al anterior, pero no hace referencia a acuerdos de cooperación no reembolsable, sino a obligaciones que se cumplen en el marco de la ejecución de proyectos derivados de acuerdos de cooperación internacional en los que el ente cooperante otorga al Perú, en calidad de donación o contribución, una suma de dinero o especies. En esa medida, la justificación para considerar que estos tratados de cooperación internacional no versan sobre obligaciones financieras del Estado, descansa en los mismos argumentos señalados en el supuesto anterior.

\subsection{Tratados que crean, modifican o suprimen tributos}

El primer párrafo del artículo 74 de la Constitución establece que:

Los tributos se crean, modifican o derogan, o se establece una exoneración, exclusivamente por ley o decreto legislativo en caso de delegación de facultades, salvo los aranceles y tasas, los cuales se regulan mediante decreto supremo.

Este artículo recoge el principio de reserva de ley en materia tributaria. Sin embargo, es importante para los efectos de este trabajo analizar los alcances de la excepción contenida en la parte final del primer párrafo del artículo 74 de la Constitución: «salvo los aranceles y tasas, los cuales se regulan mediante decreto supremo».

Para entender esta excepción, se debe tomar en consideración lo señalado en el artículo 118.20 de la Constitución:

Corresponde al Presidente de la República:

[...]

20. Regular las tarifas arancelarias. 
En este orden de ideas, si se analiza el primer párrafo del artículo 74 de la Constitución a la luz del artículo 118.20, «resulta evidente que la regulación vía decreto supremo de los aranceles y tasas, establecida en dicha norma constitucional, alude al elemento del tributo de carácter cuantitativo, mas no así al de nacimiento o generación del tributo, el que obviamente se mantiene dentro de la potestad conferida al Congreso de la República» (López, 2008, p. 35).

Así, de acuerdo con los artículos 74 y 118.20 de la Constitución, se debe interpretar que por medio de un decreto supremo «lo que se regula no es el arancel y las tasas, sino la tarifa del arancel de aduanas y la cuantía de las tasas del Gobierno Central e instituciones públicas, lo que debió expresarse en esos términos» (Zolezzi, 1994, p. 145).

Bajo este marco conceptual, si un tratado crea, modifica o suprime tributos, requerirá la aprobación previa del Congreso de la República, para garantizar el respeto del principio de reserva de ley en materia tributaria, establecido en el primer párrafo del artículo 74 de la Constitución.

El artículo 10 del proyecto sobre el perfeccionamiento interno de los tratados, sobre la base de lo expuesto, precisa que un tratado crea, modifica o suprime tributos:

10.1. Cuando establece la obligación de crear o crea un tributo, al margen de que tal tributo ya esté regulado en la legislación nacional.

10.2. Cuando establece la obligación de modificar o modifica un tributo, en cualquiera de los elementos de la norma tributaria, al margen de que la regulación interna de dicho tributo requiera o no modificaciones para adecuarse a la obligación que se deriva del tratado.

10.3. Cuando establece la prohibición de realizar el cobro de un tributo; ya sea porque obliga a suprimirlo o lo suprime, porque establece una exoneración, porque establece una exención, o por cualquier otra razón; al margen de que dicho tributo esté o no regulado en el ordenamiento jurídico nacional y de que este ordenamiento ya contenga o no la posibilidad de exonerar u otorgar una exención del pago de aquel tributo.

10.4. Cuando se establecen regímenes para evitar la doble imposición tributaria.

Tanto en el numeral 10.1 como en el 10.2 y el 10.3 recién citados, el proyecto hace referencia a dos situaciones distintas: el establecimiento de la obligación de crear, modificar o suprimir, y el supuesto en el que el tratado directamente crea, modifica o suprime tributos. En todos estos casos, el acuerdo estaría en el marco de lo establecido en el artículo 56 de la Constitución.

Si el tratado directamente crea, modifica o suprime un tributo requerirá, en atención al principio de reserva de ley en materia tributaria antes explicado, la aprobación del 
Congreso de la República. Por otro lado, si el Ejecutivo pretende obligar al Congreso a crear, modificar o suprimir un tributo, estableciendo tal obligación en un tratado, será también necesario que el legislativo apruebe el acuerdo que establezca tal obligación, pues por el principio de reserva de ley en materia tributaria, le corresponde al Congreso tomar la decisión de crear, modificar o suprimir tributos, de manera tal que el Presidente no lo puede obligar a hacerlo sin su consentimiento.

Por otro lado, los numerales 10.1, 10.2 y 10.3 se refieren, respectivamente, a tres supuestos que responden a una lógica común: cuando el tratado ordena la creación o crea un tributo que ya existe en el ordenamiento interno, cuando ordena la modificación o modifica un tributo cuya regulación interna no requiere modificaciones para adecuarse a lo establecido en dicho tratado, y cuando ordena suprimir o suprime un tributo que no está regulado en el ordenamiento interno, así como cuando exonera o establece la exención de un tributo en un supuesto en el que el ordenamiento interno ya establece tal exoneración o exención.

A primera vista se podría pensar que los tratados que recojan estos supuestos no requerirían la aprobación del Congreso, sin embargo, esa apreciación no sería correcta. Si el tratado establece la obligación de crear, modificar o suprimir un tributo, o si directamente lo hace, o si establece una exoneración o exención, instaura un régimen tributario especial que será de obligatorio cumplimiento en las relaciones entre los Estados partes en el tratado, al margen de lo regulado en sus normas internas o, sobre todo, de la eventual modificación de esas normas internas.

Así, por ejemplo, si el tratado suprime un tributo para una determinada actividad que realicen en el Perú los nacionales de otro Estado, y ese tributo no existe en el ordenamiento interno, la eventual creación de tal tributo para esa actividad por parte del Congreso de la República, no puede afectar a los nacionales del Estado con el que se celebró el tratado.

Hay que recordar que los tratados solo se pueden modificar, darse por terminados o suspenderse su aplicación, de acuerdo con las normas del propio tratado o del derecho internacional general. Esta regla es una norma consuetudinaria, que además ha sido desarrollada en varios artículos de la Convención de Viena de 1969 sobre el Derecho de los Tratados y que, incluso, está recogida en el ordenamiento interno peruano ${ }^{25}$.

De esta manera, en el ejemplo antes mencionado, la supresión del tributo que en el ordenamiento jurídico peruano no existe, impide que el Congreso de la República

\footnotetext{
${ }^{25}$ La ley 26647, que regula el perfeccionamiento interno de los tratados, recoge esta norma en su artículo 7. Por otro lado, el proyecto sobre el perfeccionamiento interno de los tratados, antes citado, en su artículo 26 también establece esta norma, por cierto, con una redacción mucho mejor que el del artículo 7 recién mencionado.
} 
lo pueda crear para gravar la actividad a la que se refiere el tratado, realizada por las personas mencionadas en ese acuerdo.

Por lo recién explicado considero que, como lo he seńalado, en todos estos supuestos, y no solo en el del ejemplo, el tratado estaría instaurando un régimen tributario especial que será de obligatorio cumplimiento en las relaciones entre los Estados partes en el tratado, al margen de lo regulado en sus normas internas o, sobre todo, de la eventual modificación de esas normas internas. En esa medida, la instauración de tal régimen tributario especial, en atención al principio de reserva de ley en materia tributaria, requiere la aprobación previa del Congreso de la República.

Adicionalmente, hay que señalar que el proyecto sobre el perfeccionamiento interno de los tratados emplea los términos «exoneración», «exención» o «supresión», con la única finalidad de abarcar todos los supuestos que en materia tributaria se podrían referir a casos en los que no se pagará un tributo. Esto se debe a que, si se emplea un único término en la ley, la redacción de los tratados usando términos distintos puede confundir a los operadores del derecho, llevándolos a considerar que el tratado no requeriría la aprobación del Congreso, cuando lo correcto es que sí requiera esa aprobación.

Ahora bien, el supuesto contemplado en el artículo 10.4 del proyecto sobre el perfeccionamiento interno de los tratados, antes citado, se explica en la medida en que los tratados que buscan evitar la doble imposición tributaria, implican por sí mismos la instauración de regímenes tributarios especiales que, por el principio de reserva de ley en materia tributaria, es una competencia del Congreso de la República, por lo que se requiere su aprobación previa.

Por otro lado, el artículo 11 del proyecto sobre el perfeccionamiento interno de los tratados establece tres supuestos en los que se debe considerar que no hay creación, modificación o supresión de tributos:

a) Cuando el tratado "modifica o dispone la modificación de las tasas de un arancel; incluso en el supuesto de la reducción de la tasa del arancel a cero» (artículo 11.1).

Líneas arriba se explicó que la regulación de las tarifas arancelarias es potestad del Presidente de la República, por tanto, si el tratado obliga a modificar o modifica tarifas arancelarias, se refiere a competencias que no se enmarcan en la reserva de ley en materia tributaria y, consecuentemente, no se requiere la aprobación previa del Congreso.

Además, debe tomarse en consideración que la reducción de la tarifa de un arancel a cero, no puede interpretarse como una supresión del tributo. En un supuesto así, el arancel sigue existiendo en tanto que su creación, la modificación de sus elementos distintos al cuantitativo, o su supresión, corresponde al 
Congreso de la República en atención al principio de reserva de ley en materia tributaria. Solamente uno de los elementos de la norma tributaria, la cuantía del arancel, habría sido establecida en cero en ejercicio de la potestad de regular las tarifas arancelarias que corresponde al presidente de la República, en atención a lo señalado en la parte final del primer párrafo del artículo 74 de la Constitución, interpretado a la luz del artículo 118.20 de la carta magna.

Así, por ejemplo, una desgravación arancelaria pactada en un acuerdo de libre comercio no implica la supresión del tributo, sino solo la reducción de su cuantía, incluso a cero, al punto que el arancel, con otra cuantía, podría seguir cobrándose a Estados que no sean parte en ese acuerdo de libre comercio. Para comprender mejor esto, es necesario recordar que la desgravación en materia tributaria implica la utilización de herramientas que permiten, en determinados supuestos, disminuir o eliminar la carga tributaria, pero que no afectan la existencia misma del tributo.

Finalmente, la única recomendación que haría sobre este punto es que se cambie la redacción del proyecto en este supuesto, de manera tal que en lugar de referirse a la "tasa» de un arancel, se refiera a la «tarifa» del arancel.

b) En los casos en los que «la creación, modificación o supresión de tributos se realiza en el marco del cumplimiento de un tratado ordinario anterior en vigor para el Perú» (artículo 11.2).

Si un tratado que ya fue aprobado por el Congreso de la República (lo que el proyecto llama tratado ordinario) establece la obligación o la posibilidad de que el Ejecutivo cree, modifique o suprima tributos en referencia a un conjunto de supuestos claramente determinados, la celebración de un tratado posterior por el que se ejecute ese tratado anterior y, por ejemplo, suprima un tributo en uno de esos supuestos determinados en el primer tratado, ya no tiene sentido que requiera la aprobación legislativa, pues en el segundo tratado no se regularía nada distinto de lo que ya fue aprobado por el Congreso.

c) Cuando el tratado dispone la creación, modificación, exoneración, exención o supresión de tributos en el marco de acuerdos de cooperación no reembolsable o de la ejecución de proyectos derivados de acuerdos de cooperación internacional en los que el ente cooperante otorga al Perú, en calidad de donación o contribución, una suma de dinero o especies ${ }^{26}$.

La justificación de esto es la misma que fue explicada en el acápite anterior al hacer referencia a los tratados que debe considerarse no versan sobre obligaciones

${ }^{26}$ El artículo 11.3 del proyecto recoge este supuesto con la siguiente redacción: «Cuando se dispone la creación, 
financieras del Estado. Someter los tratados a los que se refiere este supuesto al trámite de aprobación del Congreso de la República, por considerar que crean, modifican o suprimen tributos, puede generar que el Estado pierda la oportunidad de recibir cooperación internacional no reembolsable o la oportunidad de ejecutar proyectos concretos derivados de acuerdos de cooperación por los que recibe una donación o contribución en dinero o especies, lo que tendría enormes efectos negativos para la sociedad en su conjunto. Por ello, se propone considerar que estos tratados no crean, modifican o suprimen tributos y, por tanto, no requieren la aprobación previa del Congreso.

\subsection{Tratados que exigen la modificación o derogación de una ley o que requieren medidas legislativas para su ejecución}

La justificación para que este tipo de tratados requieran la aprobación previa del Congreso se encuentra en el hecho de que estamos: «ante facultades propias del Poder Legislativo. Así, el artículo 102 inciso 1 de la Constitución establece como atribución del Congreso: «Dar leyes y resoluciones legislativas, así como interpretar, modificar o derogar las existentes"» (Novak, 2013, p. 1051).

Por ello,

[...] la aprobación del Congreso se hace entonces necesaria en la medida que debe existir coordinación entre las normas internas que aprueba el Congreso y los tratados internacionales que impliquen la modificación o derogación de tales normas. De igual forma, se torna imperativo que los tratados que exijan medidas legislativas para su ejecución sean aprobados por el Congreso, en la medida que este órgano deberá ser quien legislará internamente para implementar el tratado. (Novak, 2013, p. 1051)

Así, el proyecto sobre el perfeccionamiento interno de los tratados, en su artículo 12, establece que:

Se considera que un tratado exige la modificación o derogación de una ley, cuando debe modificarse o derogarse una norma con rango de ley como consecuencia de la manifestación del consentimiento del Estado peruano en obligarse por este.

Se considera que un tratado requiere medidas legislativas para su ejecución, cuando su cumplimiento está condicionado a la promulgación de una o varias normas con rango de ley.

Esta propuesta es bastante sencilla, por lo que considero que no requiere mayor explicación. Sin embargo, sí es importante recalcar que la frase constitucional «medidas

numerales, citados antes, se refieren precisamente a la celebración de acuerdos de cooperación no reembolsable y a la ejecución de proyectos derivados de acuerdos de cooperación internacional en los que el ente cooperante otorga al Perú, en calidad de donación o contribución, una suma de dinero o especies. 
legislativas», está siendo interpretada como "normas con rango de ley», lo que incluye, entre otras, leyes, resoluciones legislativas y, también, decretos legislativos que, sin bien emite el Presidente de la República, requieren de autorización previa del Congreso.

\subsection{Tratados que afectan disposiciones constitucionales}

De lo regulado por los artículos 56 y 57 de la Constitución, se desprende que en el Perú existen tres procedimientos para el perfeccionamiento interno de tratados. Primero, el que se refiere a los tratados enmarcados en los supuestos del artículo 56, que requieren aprobación previa del Congreso de la República antes de la manifestación del consentimiento del Estado Peruano en obligarse por ellos. Segundo, el que se refiere a los tratados que no están enmarcados en los supuestos del artículo 56, que el primer párrafo del artículo 57 establece que no requieren tal aprobación previa y que el Reglamento del Congreso de la República llama «tratados internacionales ejecutivos», acuerdos de cuya celebración se debe dar cuenta al Congreso. Y, tercero, el que se refiere a tratados que se enmarcan en el segundo párrafo del artículo 57, que son los que se oponen a disposiciones constitucionales y que, por tanto, requieren un procedimiento especial de aprobación por parte del Congreso de la República antes de la manifestación del consentimiento del Estado en obligarse por ellos.

El segundo párrafo del artículo 57 de la Constitución establece que:

Cuando el tratado afecte disposiciones constitucionales debe ser aprobado por el mismo procedimiento que rige la reforma de la Constitución, antes de ser ratificado por el Presidente de la República.

La frase "antes de ser ratificado por el Presidente de la República», debe entenderse en el siguiente sentido: «antes de que el Presidente de la República manifieste el consentimiento del Estado en obligarse por él».

En relación a los tratados que afectan disposiciones constitucionales, el proyecto sobre el perfeccionamiento interno de los tratados precisa en su artículo 20, sobre todo por una cuestión de orden, que: «Se considera que un tratado afecta disposiciones constitucionales si se opone a algún artículo de la Constitución Política del Perú».

Por su parte, el artículo 206 de la Constitución señala que:

Toda reforma constitucional debe ser aprobada por el Congreso con mayoría absoluta del número legal de sus miembros, y ratificada mediante referéndum. Puede omitirse el referéndum cuando el acuerdo del Congreso se obtiene en dos legislaturas ordinarias sucesivas con una votación favorable, en cada caso, superior a los dos tercios del número legal de congresistas. 
En este orden de ideas, si un tratado se opone a algún artículo de la Constitución Política del Perú, deberá ser aprobado por el mismo procedimiento que rige la reforma de la Constitución, establecido en el artículo 206, en atención a lo señalado en el segundo párrafo del artículo 57. En este supuesto, entonces, se exige seguir el procedimiento de reforma de la Constitución, pero no se exige que esta sea reformada.

Ninguna de las diferentes normas internas peruanas que regulan materias vinculadas con los tratados, desarrollan el detalle del procedimiento de perfeccionamiento interno que deba seguirse en este supuesto. Sin embargo, el proyecto sobre el perfeccionamiento interno de los tratados hace una interesante propuesta al respecto que, al no ser materia de este trabajo, me excuso de explicar ${ }^{27}$.

\section{Consideraciones adicionales}

El proyecto sobre el perfeccionamiento interno de los tratados, con miras a aclarar el alcance de las disposiciones que propone, establece tres disposiciones generales sobre los tratados comprendidos en los artículos 56 y segundo párrafo del 57 de la Constitución. En el artículo 13 del proyecto se precisa que:

13.1 Se considera tratado ordinario al que, si bien la materia principal sobre la que versa no está contemplada en el artículo 56 de la Constitución Política del Perú, contiene disposiciones que sí se refieren a dichas materias.

13.2 Se considera tratado ordinario al que, pese a no regular las materias contempladas en el artículo 56 de la Constitución Política del Perú, establece la obligación de celebrar uno o más acuerdos posteriores en los que sí se regulen dichas materias.

13.3 No se considera tratado ordinario al que, pese a regular materias contempladas en el artículo 56 de la Constitución Política del Perú, se celebra con la finalidad de cumplir una obligación establecida en un tratado ordinario anterior en vigor para el Perú. Este tratado es considerado tratado internacional ejecutivo.

Basta que un tratado contenga alguna disposición referida a las materias contempladas en el artículo 56 de la Constitución, para que se considere que ese tratado requiere aprobación del Congreso de la República. Esa es la idea recogida en el artículo 13.1 recién citado.

Por otro lado, los supuestos de los artículos 13.2 y 13.3, mencionados líneas arriba, requieren ser interpretados en conjunto. La obligación de regular materias contempladas en el artículo 56 de la Constitución a través de un acuerdo posterior, implica que el tratado que contenga esta obligación estaría forzando al Congreso a aceptar

\footnotetext{
${ }^{27}$ La propuesta está regulada entre los artículos 20 a 23 del proyecto.
} 
esa regulación futura, pues, de lo contrario, se estaría incumpliendo dicho tratado. Por ello, aunque ese tratado en estricto no se enmarque en el artículo 56, requiere la aprobación del Congreso, en la medida en que quedará sujeto a la regulación futura que haga un tratado sobre temas que le compete aprobar.

Como consecuencia de lo anterior, si el Congreso ya aprobó un tratado en el que se recoge la obligación de regular en un acuerdo posterior materias contempladas en el artículo 56, ese acuerdo posterior que cumpla con la obligación aceptada ya por el Congreso, no requiere nuevamente su aprobación y debe seguir el procedimiento de perfeccionamiento interno que corresponda a un tratado internacional ejecutivo.

\section{Apunte final}

En el Perú se necesita una norma que, de manera clara y ordenada, desarrolle lo señalado por los artículos 56 y 57 de la Constitución. Estas normas de desarrollo constitucional ya existen en otros países. El proyecto sobre el perfeccionamiento interno de los tratados comentado en este trabajo, si bien abarca más temas que los aquí estudiados, se centra solo en el perfeccionamiento interno de los tratados, dejando de lado varias otras materias, algunas de las cuales ya se encuentran reguladas, pero en diferentes normas que debieran integrarse.

Definitivamente, el proyecto sobre el perfeccionamiento interno de los tratados recoge propuestas que se pueden mejorar, del mismo modo que las ideas expresadas en este trabajo. La intención de realizar estos planteamientos es iniciar un debate que considero necesario en el Perú, en el que debieran participar todos los actores involucrados en el proceso de celebración de tratados y en su posterior aplicación. Solo de esa manera se podrá ordenar y simplificar el trabajo que, ciertamente, descansa en gran medida en las labores que realiza la Cancillería y el Congreso de la República, garantizando procedimientos más eficientes de aprobación de tratados y de dación de cuenta de su celebración.

\section{Referencias bibliográficas}

Abugattás, G. (2003). Hacia una visión tridimensional de los derechos humanos y los tratados internacionales sobre derechos humanos. Revista Jurídica del Perú, 46, 81-91.

Duverger, M. (1970). Instituciones politicas y derecho constitucional. 5ta ed. Barcelona: Ariel. Jellinek, G. (2014). Teoría General del Estado. México D.F.: Fondo de Cultura Económica. López, L. (2008). La potestad tributaria en materia aduanera. Análisis Tributario, 242, 32-35. 
Novak, F. (2013). Comentario al artículo 56 de la Constitución Política del Perú de 1993. En W. Gutiérrez (dir.), La Constitución comentada (pp. 1046-1052). Lima: Gaceta Jurídica S.A.

Remiro Brotons, A. et al. (2007). Derecho internacional. Valencia: Tirant lo Blanch.

Tribunal Constitucional de la República del Perú (24 de abril de 2006). Sentencia recaída en el expediente 047-2004-AI/TC. Lima. Recuperado de https://www.tc.gob.pel jurisprudencia/2006/00047-2004-AI.html

Tribunal Constitucional de la República del Perú (5 de febrero de 2010). Sentencia recaida en el expediente 002-2009-PI/TC. Lima. Recuperado de https://www.tc.gob.pe/ jurisprudencia/2010/00002-2009-AI.html

Tribunal Constitucional de la República del Perú (19 de julio de 2011). Sentencia recaida en el expediente 032-2010-PI/TC. Lima. Recuperado de http://www.tc.gob.pel jurisprudencia/2011/00032-2010-AI.html

Zolezzi, A. (1994). El régimen tributario en la nueva Constitución. La Constitución de 1993. Análisis y comentarios. Serie de lecturas sobre temas constitucionales, 10. Lima: Comisión Andina de Juristas, pp. 141-152.

Recibido: 8 de abril de 2019 Aprobado: 2 de agosto de 2019 